\title{
Chemical Constituents and Insecticidal Activity of Senna italica Mill. from the Sudan
}

\author{
Sakina Yagi ${ }^{1}$, Sayadat El Tigani ${ }^{1}$, Mayada Ali ${ }^{1}$, Ibrahim Elkhidir ${ }^{1}$, \\ Abdelhafeez M. A. Mohammed ${ }^{2, *}$ \\ ${ }^{1}$ Department of Botany, Faculty of Science, University of Khartoum, PO Box 321, \\ Khartoum 11111, Sudan \\ ${ }^{2}$ Department of Chemistry, Alzaiem Alazhari University, PO Box 1432, Khartoum North 13311, Sudan \\ *E-mail address: ahafeez61@yahoo.com
}

\begin{abstract}
The chemical constituents and insecticidal activity of the pods of Senna italica (Caesalpiniaceae, Fabaceae) were investigated. From the chloroform extract of pods, physcion, chrysophanol, chrysophanol-10,10'-bianthrone, chrysophanol-physcion bianthrone and chrysophanolisophyscion bianthrone, were isolated and characterized using different spectral methods. The GC-MS of the $n$-hexane extract revealed that the major chemical constituents of the oil were 2,6,-di-secbutylphenol (36.69\%), di- $n$-octylphthalate $(12.06 \%)$, eicosane $(5.46 \%)$, tetratriacontane $(4.87 \%)$ and 2,2'-methylenebis[6-(1,1-dimethyl)-4-methylphenol (4.18\%). The $n$-hexane extract showed potent insecticidal activity (100\%) against Callosbruchus analis $\mathrm{F}$. This study suggests that $S$. italica pods cannot be a source of sennosides but for other bioactive compounds.
\end{abstract}

Keywords: Senna italica; Fabaceae; Caesalpiniaceae; sennosides; anthraquinone; bianthrones; insecticidal activity

\section{INTRODUCTION}

Senna L. (Fabaceae, Caesalpinioideae), a large, widespread and diverse genus, occurring mostly in the tropics and subtropics. About $80 \%$ of the species of this genus growing in American continent, while most of rest are found in tropical Africa, Madagascar, and Australia, with few species in southeastern Asia and on the Pacific Islands. No Senna species are native to Europe. Species of Senna were formerly included among the approximately 600 species of Cassia L. [1]. Subsequent taxonomic treatments subdivided this large genus into the smaller Cassia, Senna and Chamaecrista Moench and ascribed these three genera to subtribe Cassiinae [2]. In the recent monograph, Senna comprised approximately 260 species [2], which later increased to 350, mainly as a result of new nomenclatural combinations in non-American taxa [3]. The separation of Senna from Cassia was confirmed by further taxonomic [4], structural [5], and phenetic studies [6].

Senna italica Mill. grows naturally throughout the Sudan. It is most famous indigenous medicinal plant of the Sudan. Many species of the genus Senna are widely used traditionally to treat a number of ailments such as intestinal complications, haemomorphoids, circulatory 
system problems, calculi in the urinary system and sexually transmitted diseases [7]. The pods of Senna plant are rich source of bioactive compounds widely used as laxative [8].

Herbalists in the Sudan used, unintentionally, to mix Senna italica with Senna alexandrina Mill. (Syn. Cassia senna L., C. acutifolia Del) because their morphologies are very closes and cause confusion between the two species. However, confusion in the proper taxonomical identification of these two species could exist since they are usually grown together in nature and minor differences can be noticed. For example, the pods of $S$. italica are curved while those of $S$. alexandrina are broader and oblong. Previous phytochemical studies of $S$. italica have resulted in the isolation of $\beta$-sitosterol, stigmasterol, $\alpha$-amyrin and 1,5-dihydroxy-3-methyl anthraquinone [9]. The active laxative principles of $S$. alexandrina are the sennosides [10]. The literature survey of Cassia spp. revealed the presence of glycosides, sterols, flavonoids, saponins and alkaloids [11]. The objective of this study was to detect the presence of sennosides in S. italica pods, in addition, to the chemical investigation of these pods and the insecticidal activity of plant extracts.

\section{EXPERIMENTAL}

\section{1. Materials and Methods}

\section{1. 1. Plant material}

The plant materials were collected in 2009 from Elobeid (western Sudan). A voucher specimen (SI 001) has been lodged at the Botany Herbarium, Faculty of Science in University of Khartoum for verification purposes.

\section{1. 2. Instrumental techniques}

NMR spectra were recorded at room temperature in $\mathrm{CDCl}_{3}$ on $400 \mathrm{MHz}$ Bruker AVANCE III spectrometer. Mass spectra were determined at $70 \mathrm{eV}$ using VG MASSLAB model VG 12-250 spectrometer. IR spectra were recorded on Perkin-Elmer FT 1600 spectrophotometer. UV spectra were measured using Milton Roy spectronic 1001 plus. The GC-MS analysis was carried out using QP 20-10 Shimadzu GC-MS equipment [19,20].

\section{1. 3. GC-MS analysis of $\boldsymbol{n}$-Hexane Extract}

The GC-MS analysis of $n$-hexane extract was carried out after conversion of the lipid material into the corresponding methyl esters [17].

The samples were analyzed using QP 20-10 Shimadzu GC-MS equipment. A Wiley 229 library search was conducted on major peaks of sample in order to identify the components of the sample. The relative percentage of each compound was determined.

\section{1. 4. Extraction and Chromatographic Separation}

Extraction and isolation of compounds: $1.0 \mathrm{~kg}$ of the ground dry pods was soaked for $48 \mathrm{~h}$ in $n$-hexane, chloroform and $\mathrm{MeOH}$ separately and successively, and then each extract was concentrated under reduced pressure and yielded 16.0, 24.0 and $26.0 \mathrm{~g}$ respectively.

The chloroform extract (10.0 g) was subjected to flash column chromatography on oxalic acid impregnated silica gel column using gradient mixture of petroleum ether:EtOAc as an eluent. Eight fractions were collected depending upon the TLC pattern. Fraction 3 was subjected to column chromatography using petroleum ether: EtOAc gradient, where it gave 
compound 1 (12 mg). Fractions 4 and 5 were applied separately to preparative TLC using solvent system $n$-hexane: EtOAc (9:1) as an eluent to give compounds 2 (16 mg) and 3 (14 $\mathrm{mg}$ ). Fraction 7 was subjected to column chromatography using solvent system $n$-hexane: EtOAc (8:2) as an eluent to give a mixture of compounds $\mathbf{4 a}$ and $\mathbf{4 b}(9 \mathbf{m g})$.

The isolated compounds were identified by using spectroscopic techniques and comparing the values with those reported in literature as well as comparison with reference materials.

\section{1. 5. Insecticidal activity}

Tribolium castaneum and Callosbruchus analis (common grain pests) were used to determine the insecticidal activity of the plant extracts as described by Naqvi \& Parveen [18].

The insecticidal property of $n$-hexane, chloroform, and methanol extracts of $S$. italica was investigated against $T$. castaneum and $C$. analis in comparison with commercial insecticide Permethrin. $2.0 \mathrm{mg}$ of different extracts were added separately to DMSO $(2.0 \mathrm{~mL})$ and diluted to $5.0 \mathrm{~mL}$. From this, $0.5 \mathrm{~mL}$ of solution was uniformly applied to a $9.0 \mathrm{~cm}$ disk of filter paper (Whatman No.1) and placed in a Petri dish.

Plates were left for $24 \mathrm{~h}$ to dry. Twenty adult insects, less than 1 month old, were introduced into the dish $5 \mathrm{~min}$ later and the dish was covered. Another batch, supplemented with reference insecticide, was used. A control with DMSO alone $(2.0 \mathrm{~mL})$ was made. For each preparation, triplicates were made. The number of dead insects was determined $24 \mathrm{~h}$ after application. Survival of insects can be assessed by calculating the percentage of inhibition or mortality.

\section{RESULTS AND DISCUSSION}

Five compounds were isolated and identified from $S$. italica pods. Compounds 1, 2 and 3 were identified as physcion [12], chrysophanol [13] and 10,10'-chrysophanol bianthrone [14] respectively by comparing their TLC chromatograms, EI-MS, ${ }^{1} \mathrm{H}$ NMR and ${ }^{13} \mathrm{C}$ NMR spectra with authentic samples and published data.

The ${ }^{1} \mathrm{H}$ NMR spectrum of compound 4 is not consistent with that of a pure compound. Signals corresponding to the protons of chrysophanol, physcion and isophyscion-9-anthrone moieties of the two dimmers are clearly seen.

The signals of the benzylic methane protons of the two dimmer are separated by 0.10 ppm (4.35 and $4.45 \mathrm{ppm})$. EIMS $(70 \mathrm{eV})$ of this compound does not show molecular ions of the dimmer but fragment ions at $\mathrm{m} / \mathrm{z}$ values of 270 (HRMS 270, 0894, calculated for $\mathrm{C}_{16} \mathrm{H}_{14} \mathrm{O}_{4}, 270.0892$ ), 269 (HRMS 269.0832, calculated for $\mathrm{C}_{16} \mathrm{H}_{13} \mathrm{O}_{4}, 269.0831$ ), 255 (HRMS 255.0676, calculated for $\mathrm{C}_{15} \mathrm{H}_{13} \mathrm{O}_{3}, 255.0657$ ) and 240 (HRMS 240.0791, calculated for $\mathrm{C}_{15} \mathrm{H}_{12} \mathrm{O}_{3}, 240.0786$ ) are observed.

The fragment ions at $\mathrm{m} / \mathrm{z} 270$ and 269 correspond to physcion or isophyscion-9anthrone and those at 241 and 240 belong to chrysophanol-9-anthrone. According to these spectroscopic evidences and data reported in the literature [14], compound 4 is identified as a mixture of chrysophanol-physcion bianthrone (1,1,8,8'-tetrahydroxy-6'-methoxy-3,3'dimethyl-10,10'-bianthracen-9,9'-dione) $\mathbf{4 a}$ and chrysophanolisophyscion bianthrone (1,1,8,8'-tetrahydroxy-7'-methoxy-3,3'-dimethyl-10,10'-bianthracen-9,9'-dione) 4b (Fig. 1). 
<smiles>[R]c1cc(O)c2c(c1)C(=O)c1cc([R])cc(O)c1C2=O</smiles>

$\mathbf{R}_{1} \quad \mathbf{R}_{2}$

$1 \quad \mathrm{CH}_{3} \mathrm{OCH}_{3}$

$2 \quad \mathrm{H} \quad \mathrm{CH}_{3}$<smiles>[R2]c1cc2c(c(O)c1[R])C(=O)c1c(O)cc(C)cc1C2C1c2cccc(O)c2C(=O)c2c(O)cc(C)cc21</smiles>

$\mathbf{R}_{1} \mathbf{R}_{2}$

$3 \mathrm{H} \quad \mathrm{H}$

$\begin{array}{llll}4 \mathbf{a} & \mathrm{O} & \mathrm{OCH}_{3}\end{array}$

$4 \mathbf{b} \quad \mathrm{OCH}_{3} \quad \mathrm{H}$

Fig. 1. Structures of compounds isolated from Senna italica.

The main constituents of $n$-hexane extract were found to be 2,6,-di-sec-butylphenol $(36.69 \%)$, di- $n$-octyl phthalate $(12.06 \%)$, eicosane $(5.46 \%)$, tetratriacontane $(4.87 \%)$ and 2,2'-methylenebis[6-ter-butyl-4-methylphenol] (4.18\%).

The oil of $S$. italica contains some components that have been reported to exhibit various biological activities. Di- $n$-octylphthalate showed potent antifouling activities against algal spore and mussel attachment [15].

The $n$-hexane extract showed a strong insecticidal activity against Callosbruchus analis whereas chloroform and methanol extracts were inactive. None of the three extracts showed insecticidal activity against Tribolium castaneum Herbst. The insecticidal activity of the $n$ hexane extract dependent on the active chemical principles and the gross sensitivity of the target pest to these principles [15]. The large proportion of fatty acids might have contributed to the activity of the oil against $C$. analis.

Hexadecanoic acid is known to possess a variety of medicinal and pharmacological properties such as larvicidal effect, and antiplasmodial activity on Plasmodium falciparum [16] (Table 1). 
Table 1. Screening results on insecticidal effects of plant extracts at concentration $1.0 \mathrm{mg} / \mathrm{mL}$.

\begin{tabular}{|c|c|c|c|}
\hline Extract & \multicolumn{3}{|c|}{ Insecticidal activity } \\
\hline & & \multicolumn{3}{|c|}{$\%$ Mortality } \\
\hline & T. castaneum & C. analis & STD Drug * \\
\hline n-Hexane & 0.0 & 100 & 100 \\
\hline Chloroform & 0.0 & 20.0 & 100 \\
\hline Methanol & 0.0 & 20.0 & 100 \\
\hline
\end{tabular}

* Permethrin

Values represent percentual mortality $(\mathrm{n}=3)$ of $T$. castaneum and C. analis after $24 \mathrm{~h}$ compared to a control treated with the DMSO onl.y

\section{CONCLUSION}

The chemical investigation of the medicinal plants used traditionally to cure diseases is so important for quality control of these herbs. The results of the present study indicate that the $n$-hexane extract of $S$. italica had substantial insecticidal activity in the same order as the standard permethrin for the tested organism T. analis. The findings support the use of this plant in folk medicine for the treatment of some diseases.

\section{ACKNOWLEDGMENTS}

Authors are grateful to Professors A. Pelter and R. Ward at Department of Chemistry, University of Swansea, United Kingdom, for their interest and spectral analysis.

\section{References}

[1] H. S. Irwin, B. L. Turner, Amer. J. Botany 47 (1960) 309-318.

[2] H. S. Irwin, R. C. Barneby, Brittonia 37 (1982) 192-194.

[3] B. R. Randell, B. A. Barlow, Senna Flora of Australia 12 (1998) 89-138.

[4] B. R. Randell, J. Adelaide Bot. Gard. 12 (1990) 165-272.

[5] S. C. Tucker, Amer. J. Botany 83 (1996) 687-711.

[6] T. Boonkerd, S. Pechsri, B. R. Baum, Plants System. Evol. 252 (2005) 153-156.

[7] P. Masoko, S. S. Gololo, M. P. Mokgotho, J. N. Eloff, R. L. Howard, L. J. Mampuru, Afr. J. Tradit, Complement Altern Med. 7 (2010) 138-148.

[8] WHO. Monograph on Selected Medicinal Plants. Vol. I (1999) p 250. 
[9] M. H. Kazmi, A. Malik, S. Hameed, N. Akhtar, S. N. R. Ali, Phytochermistry 36 (1994) 761-763.

[10] A. Stoll, B. Becker, A. Helfenstein, Helv. Chim. Acta 33(1950) 313-336.

[11] S. Ahmed, A. Zahid, S. Abidi, S. Meer, IOSR J. Pharm. 2 (2012) 380-384.

[12] Y. Wu, C. Zheng, L. Qin, L. Sun, T. Han, L. Jiao, Q. Zhang, J-Z. Wu, Molecules. 14 (2009) 573-583.

[13] R. Liu, A. Li, A. Sun, J. Chromatography A 1052 (2004) 217-221.

[14] G. Alemayehu, B. Abegaz, G. Snatzke, H. Duddeck, Phytochemistry 32 (1993) 1273-1277.

[15] D. Obeng-Ofori, C. H. Reichmuth, J. Bekele, A. Hassanali, J. Appl. Entomology 121 (1997) 237-243.

[16] L. Guoqing, H. Zhaojun, M. Lili, Q. Xiaron, C. Changkun, W. Yinchang, J. Insect Physiol. 47 (2001) 951-956.

[17] N. Yayli, Z. Kiran, H. Seymen, H. Genc, Turk. J. Chem. 25 (2001) 391-395.

[18] S. N. H. Naqvi, F. Parveen, Pak. J. Entomology 6 (1991) 35-44.

[19] Abdelhafeez M. A. Mohammed, Amna M. Ibrahim1, Ayat A. Omran, Moawia E. Mohamed, Sumaya E. M. Elsheikh, International Letters of Chemistry, Physics and Astronomy 9(1) (2013) 25-30.

[20] Abdelhafeez M. A. Mohammed, Philip H. Coombes, Neil R. Crouch, Dulcie A. Mulholland, International Letters of Chemistry, Physics and Astronomy 9(2) (2013) 116-124. 